\title{
قراءة نقدية لآراء الفارابي الفلسفية -نظرية النفس انهوذجاً-
}

أ.م.د. أياد كربيم الصلاصي

كلية الآداب - جامعة واسبط

توطئنة:

منذ أن اتهم ((ابن طفيل)) في قصته(حي بن يقظان) الفار ابي بـالتردد والاضطر اب في أمر النفس،

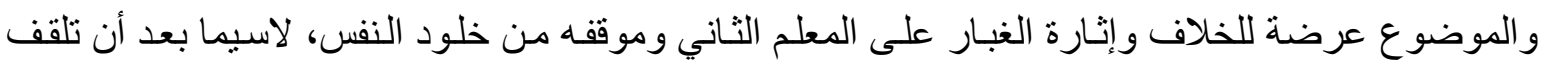
المحدثون ذلك الاتهام وبنوا عليه نتائج جانبَها الصو اب في كثير من الأحيان ('). وسبيلنا الوحيد لتحقيق هذه القضية هو استعر اض ر أي ابن طفيل، والتثبت من صحة مـا نُسب إلى الفـارابي، ثم عرض آر آراء الأخير من و اقع نصوصه الثابتة لاستخلاص النتائج النهائية، دونما إغفال لآراء المحدثين في هذه المسألة:

يقول ابن طفيل (وأما ما وصل إلينا من كتب أبي نصر فأكثر ها في المنطق ومـا ورد منها في الفلسفة

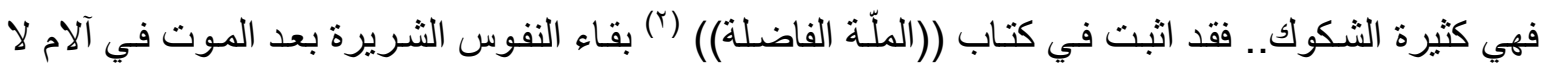

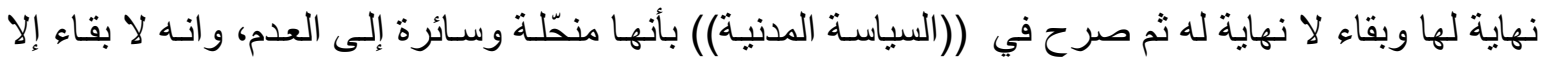

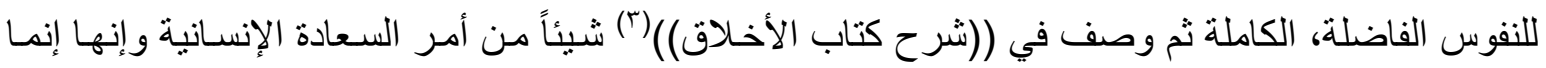
تكون في هذه الحياة التي في هذه الدار، ثم عقب ذلك كلامـاً هذا معناه"وكل مـا يذكر غير هذا فهو هذيان

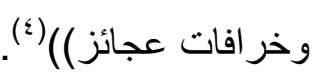

يبدو إن ابن طفيل يثير في قوله ((بقاء النفوس الثريرة بعد الموت في آلام لا نهاية وبقاء لا نهاية لـه))

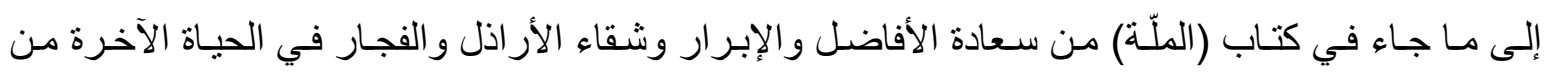

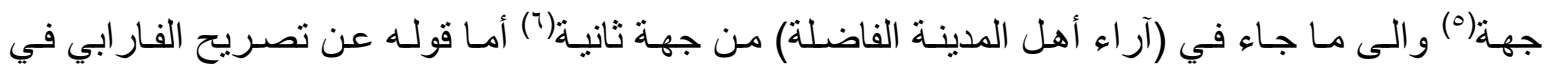

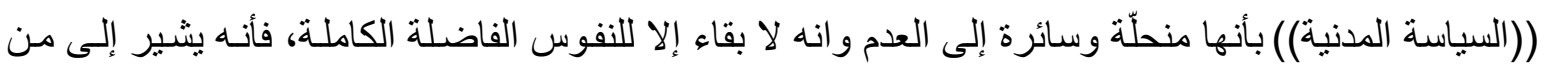

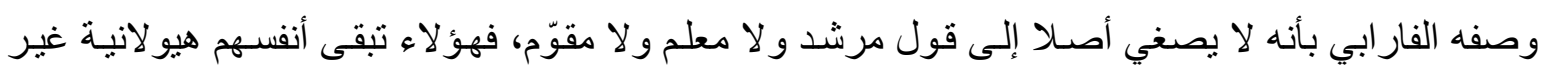
مستكملة استكمالاً تفارق به المادة حتى إذا بطلت المادة بطلت هي أيضاًً (Y). فإذا ما أخذنا بالحسبان عدول الفار ابي عن رأي أرسطو بعد النفس صورة للجسد(^) إلى عدّها جوهر اً

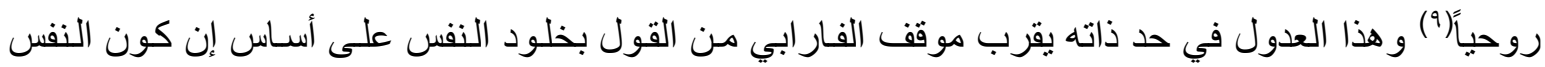
صورة للجسد قد يعني فيما يعنيه فناء تللك الصورة بفناء الجسد، حيث لا يمكن إن توجد الصورة دون وجود المادة المهيئة لها، كمـا إن القول بـأن النفس جو هر روحي مفارق يقرّب أيضـاً موقفه بشكل كبير من فكرة

\section{وحدة النفس وقواها:}

النفس في نظر الفار ابي واحدة بالذات ولكنها متعددة القوى، تفعل كل من تلك القوى أفعالها بـآلات

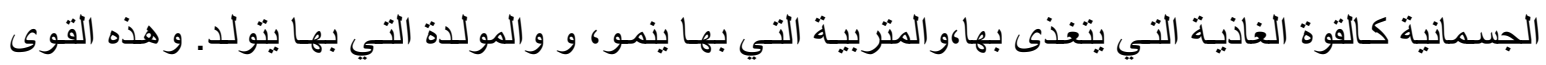
التثلاث أقسـام تجمعهـا القوة النباتيـة. وكذلك القوة الثـهوية وهنـاك القوى المدركة التي تجمـع القوى الحسية وهية 
و المتخيلة. هذه القوى كلها أفعالها بالآلات الجسمانية. وهناك قوى أخرى تفعل أفعالها بـلا آلة جسمانية وهي القوة العقلية التي تسمى بالقوة الناطقة والتي تختص بـالنفس الإنسانية(' ') إذ أن ((للإنسـان من جملـة الحيوان

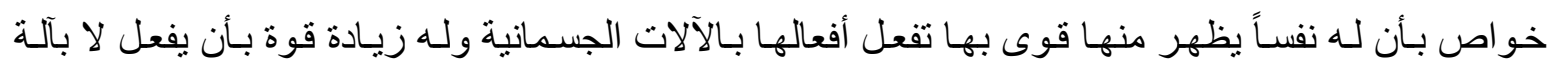
جسمانية وتلك قوة الفعل (هكذا وردت في النص و الصحيح حسب رأي المؤلف: قوة العقل) ومن تلك القوى الغاذية و المربية و المولدة ولكل واحد من هذه قوة تخدمها ومن قو اها المدركة القوى الظاهرة الإحساس الباطنة

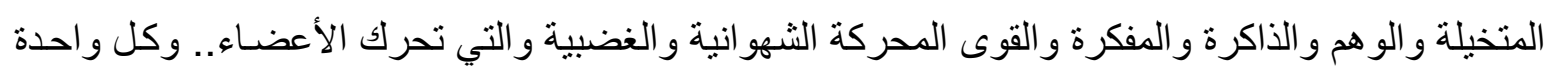

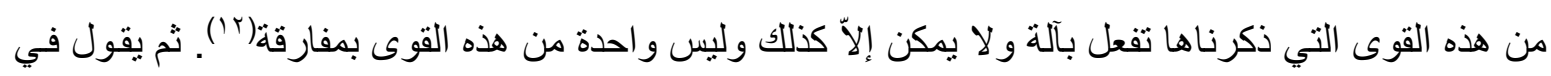

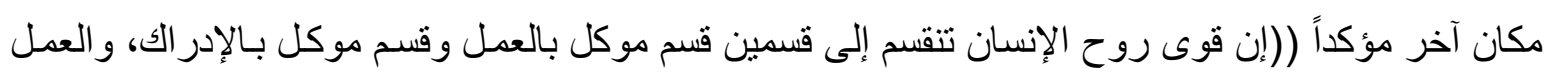
ثلاثة أقسام نباتي وحيو اني و إنسـاني والإدر الك قسمان حيو اني و إنسـاني. و هذه الأقسـام الخمسـة موجودة في في

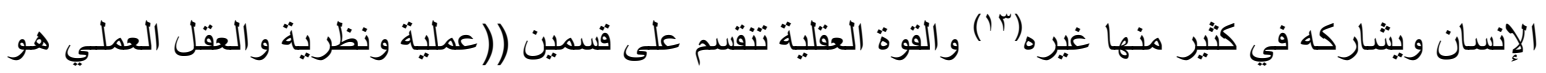

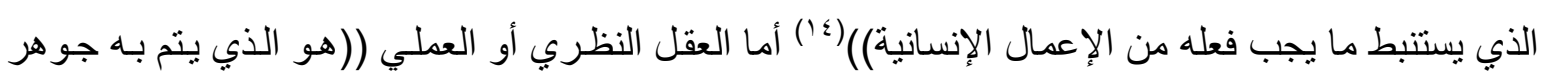
النفس ويصير جو هراً عقلياً بالفعل)(10) والقوة الناطقة التي تجمع بين العقلين المذكورين هي ((التي بها

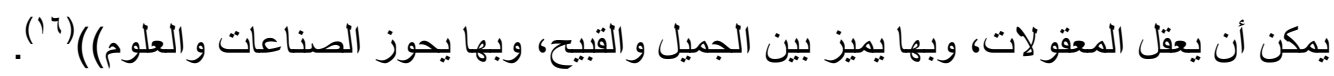
و هذه القوى للنفس ليست في مرتبة واحدة، بل أفضل القوى النفسانية على الإطلاق هي القوة الناطقة.

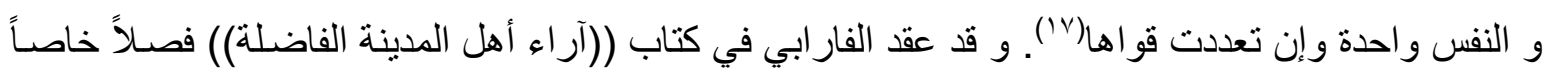
بعنوان (كيف تصير هذه القوى و الأجزاء نفساً واحدة؟) بَيَن فيه أن تللك القوى جميعها مرنبة بحيث تكون كل

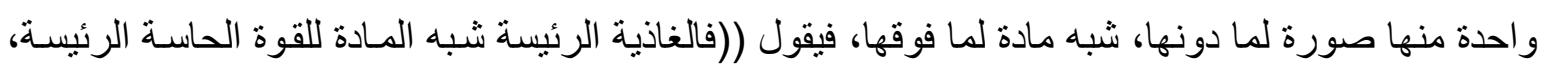
و الحاسـة صـورة في الغاذيـة. والحاسـة الرئيسـة شبه مـادة للمتخيلة، والمتخيلـة صـورة في في الحاسـة الرئيسـة. و المتخيلة الرئيسة مادة للناطقة الرئيسة، والناطقة صورة في المتخيلة، وليست مادة لقوى أخرى. فهي صورة ولئه

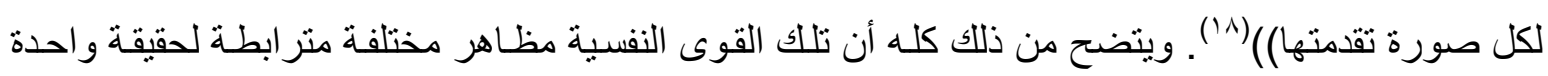
هي النفس(9)

\section{الصلة بين النفس والجسد:}

يذهب الفـار ابي في مسـألة العلاقـة بين النفس و الجســ مذذهباً فيثاغوريـاً مصبو غاً بـروح أفلاطونيـة، فيصور الصلة بينهما كصلة السجين بسجنه، منطلقاً من القاعدة اليونانية التي نظرت إلى المادة و كأنها عنصر

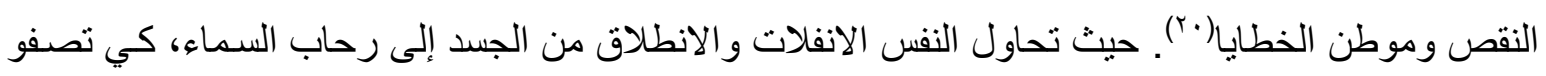
صورة وتسمو ذاتاً، فتحقق كمالها وسعادتها (وأراد أي- أفلاطون- برجوع النفس إلى عالمها عند الإطلاق من محبسها أن النفس مادامت في هذا العالم فأنها مضطرة إلى مسـاعدة البدن الطبيعي الذي هو محلها كأنها تشتاق إلى الاستر احة. فإذا رجعت إلى ذاتها فكأنها قد انطلقت من محبس مؤذٍ إلى حيز هـا الملائم المشاكل هون

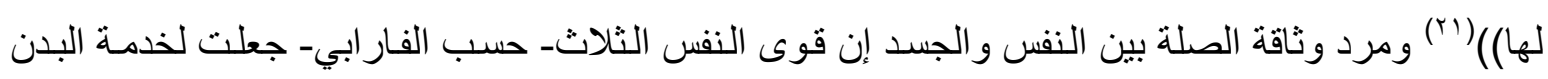
وتللك الخدمة راجعة إلى خدمة القوة الناطقة ((فالقوة الغاذية التي في الإنسان إنما جعلت لتخدم البدن، وجعلت

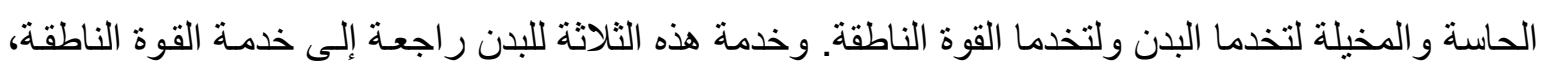


إذ كان قو ام الناطقة أولاً بالبدن)(rr) والفـار ابي يرى إن القلب هو سبب التغذيـة، والنزوع و الحو اس سبب

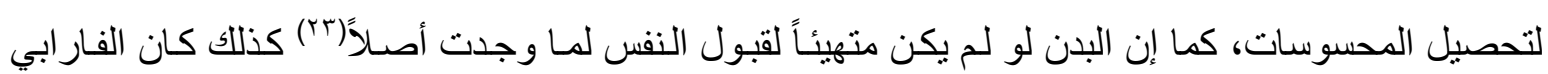
يرى إن النفس تصل إلى السعادة و التي هي الخير المطلوب لذاته بأفعال إرادية، بعضها أفعال فكريـة وبعضـها

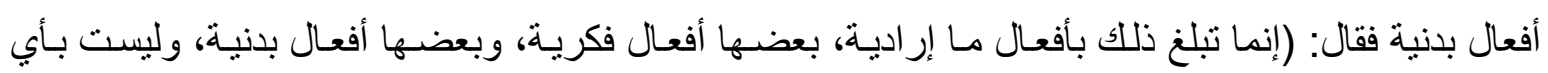

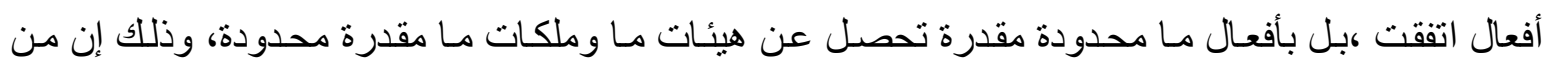

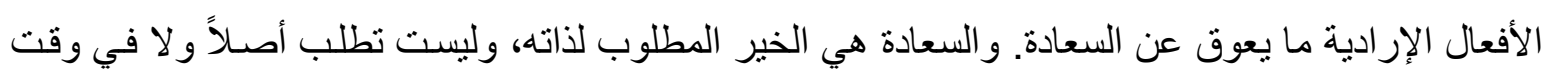

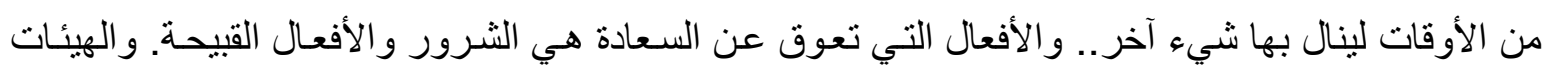
و الملكات التي عنها هذه الأفعال هي النقائص و الرذائل و الخسائس) (ءع).

المعاد عند الفارابي:

للفار ابي نصوص صريحة ليست فيها شبهة أو غموض و لا تحتمل التأويل في خلود النفس وبقائها بعد الموت، فها هو يقول: (و إنها- النفس- باقية بعد موت البدن ليس فيها قوة قبول الفساد وان لها بعد المفارقة أولاً

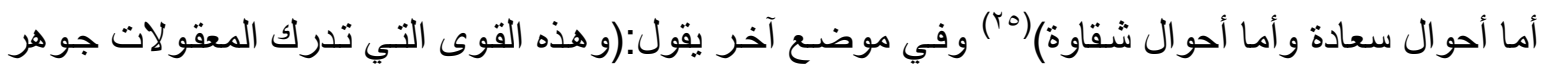

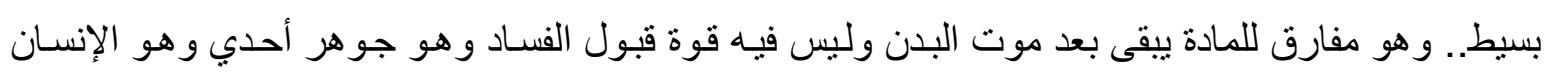
على الحقيقة) (ז') والسؤال التالي يفرض نفسه هنا: من أين أتت تلكم الثكوك التي أثنار إليها ابن طفيل، والتي ألقت

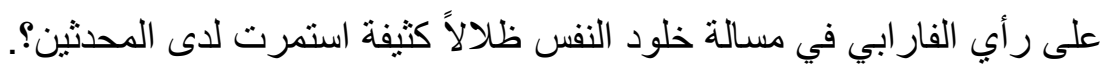
للإجابة على هذا السؤال ينبغي أولاً عرض تفصيلي لآراء الفارابي في هذه المسألة: الرأي الأول: القول بخلود النفس الإنسانية جميعاً وبلا تفرقة، إذ (للنفس بعد موت البدن سعادات وشقاو ات

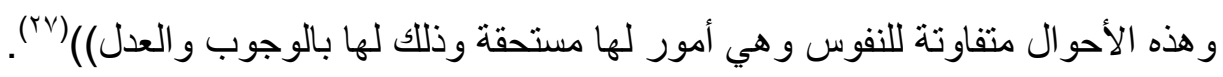
الرأي الثاني: القول بثلاثة أنواع من النفوس، وهذا التقسيم الثلاثي سيخضع للمناقشة لاحقاً: أـ- النفوس الفاضلة التي أدركت السعادة. وأخذت بأسبابها وهي نفوس أهل المدينة الفاضلة التي تبقى بعد الموت سعيدة وتزداد سعادتها كلما جاءها فوج آخر من جنسها (و إذا مضت طائفة فبطلت أبدانها، وخلصت

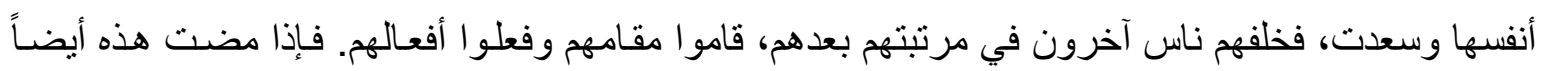
وخلت صـاروا أيضـاً في السعادة إلى مراتب أولئلك الماضين، واتصل كل واحد بشبيههة في النوع و والكميـة و الكيفية و لأنها كانت ليست بأجسام صار اجتماعها ولو بلغ ما بلغ غير مضيق بعضها على بعض مكانها، إذا ولها كانت في أمكنة أصلاً فتلاقيها واتصال بعضها ببعض ليس على النحو الذي توجد عليه الأجسام وكلما كثرت الأففس المتنـابهة المفارقة و اتصل بعضـها ببعض، وذلك على جهة اتصـال معقول بمعقول كان التذاذ كل

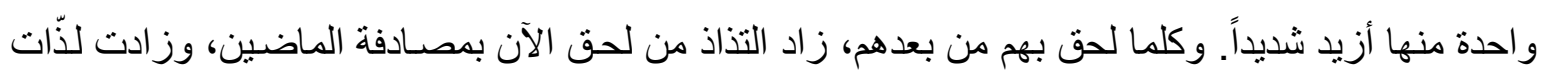

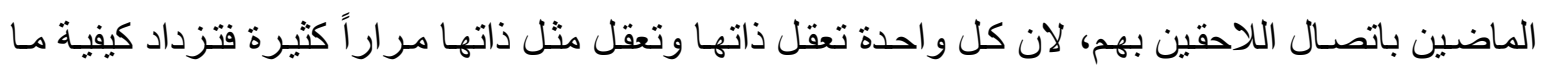

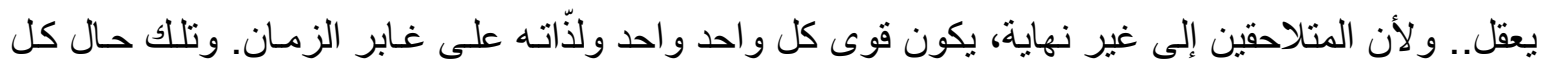


طائفة مضت)(r^) ويؤكد هذه الفكرة بنص آخر إذ يقول: ((و أهل المدينة الفاضلة لهم أشياء مشتركة يعلمونها ويفعلونها... وتلك حال الأفعال التي ينال بها السعادة فإنها كلما زيدت منها وتكررت وواضب الإنسـان عليها، صيرت النفس التي شـأنها أن تسعد أقوى و أفضل و أكمل إلى أن تصدير من حد الكمال إلى أن تستغني عن المادة، فتحصل متبرئة منها، فلا تتلف بتلف المادة، و لا إذا المادة بقيت احتاجت إلى مادة)(ب(ج). ب- نفوس أهل المدينة الفاسدة التي أدركت السعادة ولكنها لم تأخذ بأسبابها. وهي كذلك خالدة تبقى بعد الموت ولكنها في شقاء لانشـالها بـالأمور الحسية والملذات الجسمية. وكلمـا أنظمّت إليها نفوس من جنسها زادت شقاؤها ((كذلك الجزء الناطق مادام منشاغلاً بما تورده الحو اس عليه، لم يشعر بأذى ما يقترن بـه من الهيئات

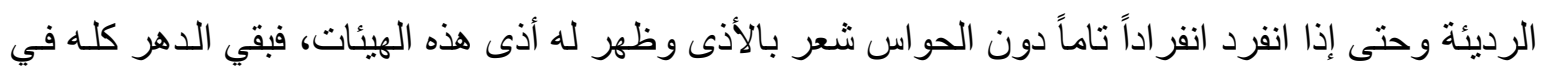
أذى عظيم. فان الحق بـه من هو في مرتبتهـه من أهل تلك المدينة، ازداد أذى كل واحد منهم بصـاحبه، لان

المتلاحقين بلا نهاية تكون زيادات أذاهم في غابر الزمان بلا نهاية. فهذا هو الثقاء المضاد للسعادة))(·־). ج- النفوس الجاهلة التي هي وحدها تفنى و هؤلاء (على حد قول الفار ابي) هم الهالكون الصـائرون إلى العدم (أما أهل المدن الجاهلية، فأن أنفسهم تبقى غير مستكملة ومحتاجة في قو امها إلى المـادة ضرورة إذهم لم يرتسم فيهما رسم حقيقة بشيء من المعقو لات الأول أصلاً. فإذا بطلت المادة التي بها كان قو امها بطلب القوى التي كان شأنها أن يكون بها قو ام ما بطل.. و هؤ لاء هم الهالكون و الصائرون إلى العدم، على مثنال مـا يكون عليه

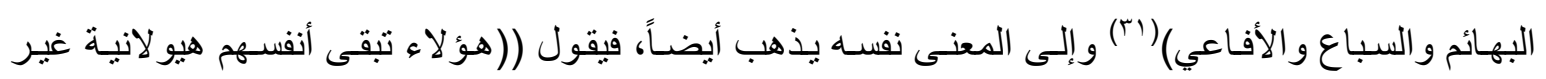
مستكملة استكمالاً لا تفارق به المادة حتى إذا بطلت المادة بطلت هي أيضاً))(باعَ).

\section{والآن ومن خلالها عرضنا لآراء الفارابى المفصلة حول هذه القضية نخلص إلى ما يلى:}

1 - اثبت الفار ابي خلود النفس بشكل عام دونمـا تحديدها بفاضلة أو جاهلة، وذلك بنصوص صـريحة قاطعة ليس فيها أي لبس أو غموض. وقد ورد هذا الإثبات في ثلاثة من كتبه هي: (الدعاوى القلبية)، (عيون

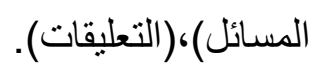

r- في كتابي (المدينة الفاضلة)، و(السياسة المدنية) اثبت خلود النفس الجاهلة. فمرة قـال بخلودها في

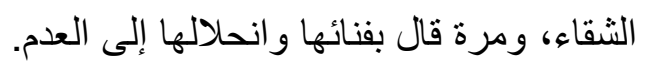

r- إذن فالفار ابي يتبت خلود النفس الفاضلة بشكل قاطع، وخلود النفس الجاهلة بشكل متردد.

من هنـا فـان شقة الخـلاف باتـت ضـيقة جداً، وتتحصـر في خلود النفس الجاهلـة فحسب. وتفسير ذلك، إن الفار ابي حينما تعرض لمصير النفس في هذا الموضوع من كتابي (المدينـة الفاضلة) و(السياسـة المدنيـة) لم

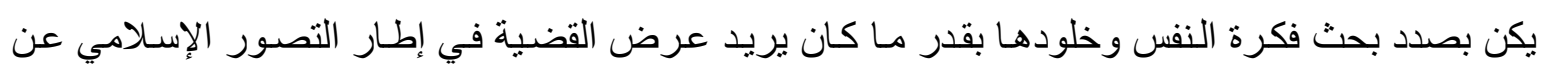
الثو اب والعقاب في اليوم الآخر، حيث تجزى كل نفس ما كسبت، وحيث العقاب درجات حسب أفعال الإنسـان في هذه الدنيا والإشار ات إلى ذلك كثيرة في القرآن وكتب الحديث وكتب التفسير ـ وقد أكد على ذلك بعض وهل

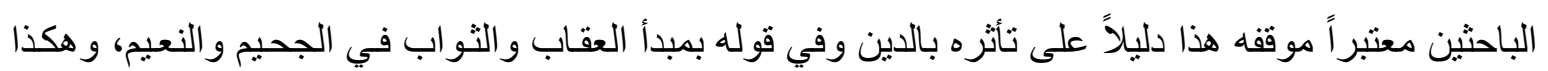

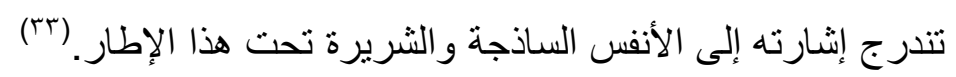


أي عند تحكيم الرأي بنصوص الفار ابي نجد إن المقصود من أضعاف خلود بعض الأنفس الثريرة هو تحقيق لطبيعـة العقيدة الدينيـة التـي أكدت تصنيف الأنفس الإنسانية إلى مر اتب في سعادتها، حسب أفعالها

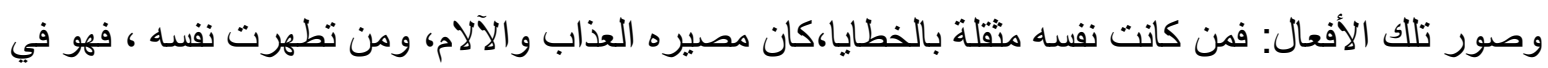
أعلى عليين، مع الثهداء أو الصديقين، وحسن أولئك رفيقاً.. تلك هي نظرة الإسلام، وتلك هي نظرة الكيرة الفار ابي بالذات وليس في تنظيره هذا ما يدفع إلى القول بأنه تتاقض مع نفسه، بل على العكس كان أمينـاً معها، ولكن إدر الك وفهم بعض الباحثين العرب لهذه النصوص هو الذي فاد إلى هذه الأحكام المبتسرة(؟r).

وو اضح إن الفار ابي يميز بين حالين فقط للنفس بعد مفارقتها البدن هما: حال السعادة وحال الثقاء أمـا النفوس التي صفت وعلمت الخير وعملت بـه خالـة في السـعادة و النعيم و أمـا النفوس التي علمت الخير

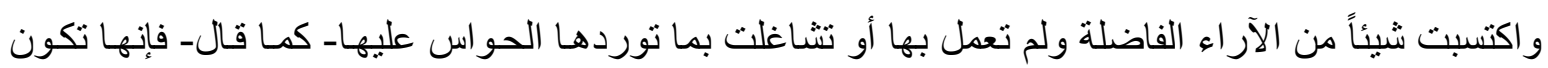
خالدة في الثقاء. وليس من مبرر لاستنباط حالة ثالثة للنفس لا هي خالدة في النعيم أو الثقاء و إنما صائرة إلى

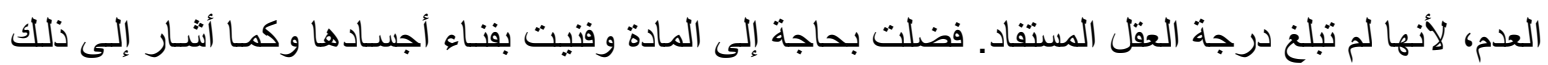

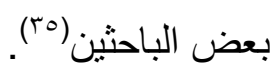
إذن الفار ابي لم يثر إلا إلى وجود حالتين كما لاحظنـا من النصوص السـابقة. أمـا الأقو ال التي بستند عليها هؤلاء حول مصير نفوس أهل المدن الجاهلية ،فإنها تدخل في بـاب الحديث عن الثواب و العقاب في اليوم الآخر و العقاب درجـات كمـا أوضحنا، وقد تكون الإشـارة في ذللك إلى أراء بعض الفلاسفة اليونـان، و الذين كثيراً ما يسميهم الفار ابي بـ (القدماء) حيث يقول: ((رأى القدامى انه تتولد من هذه النفوس الإنسانية

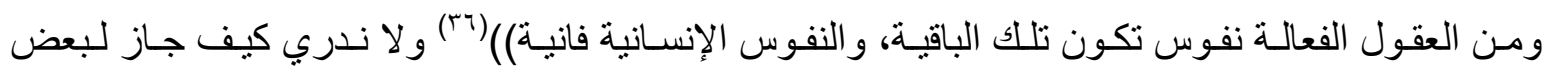

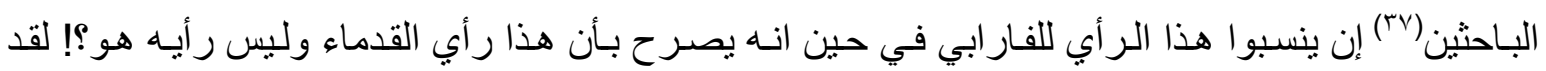

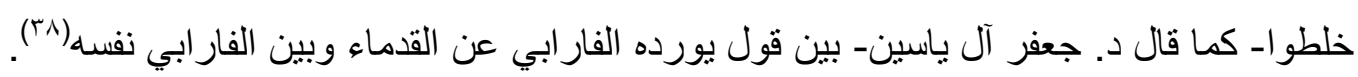
لقد جعل الفار ابي النفس جوهراً حادثاً، واعتبر في تقرير مصير ها عنصري العلم والعمل، ووصف

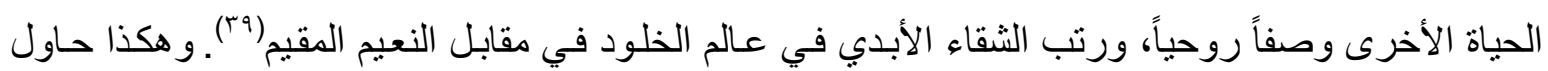
الفار ابي في مسألة مصير النفس إن يوفق بين الدين و الفلسفة، فإذا بـه يغضب الدين ولم يرض الفلسفة، وذلك متأت من نوفيقيته بين جميع مذاهب الفلسفة، فهو أفلاطوني، أرسطو طاليسي، اسكندر اني إثـر اقي، إسـامي في آن واحد(·). منات.

\section{رؤية نقدية:}

لايمكن لاي كـان ان ينكر فضـل العقل البشـري ودوره في ادر الك الامور و الحقائق، بـل لا يمكنه الا

الاعتر اف بقدرته على فهم الحقائق الكونية والاكتشافات العلمية وصنع الالات الصناعية العظيمـة، فضلا عن قدرته وفضله في وضع النظم والقوانين المختلفة وفي بيان القيم الاخلاقية والاجتماعية وفي تاثير تللك القيم في النفوس. كذلك لا يمكن الا الاعتر اف بفضل الانسـان على سـائر المخلوقات الارضـية، بهذا العقل، الا ننـا نعترف بكل ذلك في اطار دائرته المحدودة، فإن العقل البشري مخلوق من مخلوقات الله تعالى وهو بهذه الحيثية محدود وذو قدرة معينة كما لكل شيء في هذه الدنيا حدود معينة، حتى للكون نفسـه. نعم نحن ندرك 
وجود الله، بواسطة اثاره الكونية ونزداد ايمانا بـه بو اسطة ماجـاء في وحيه الالهي دون الوصـول الى معرفـة حقيقة ذاته تعالى ونعد كل هذه الامور و الحقائق في دائرة العقل، امـا الامور الغيبية مثل كيفيـة المعاد ومـا سوف يقع في الحياة الاخرى فيجب ان لانحكم عقولنا القاصرة فيها، بل علينا ان نرجع فيها الى الوحي الالهي لمعرفة تللك الحقائق الغيبية من كتاب الله تعالى. ولما كانت كيفية المعاد و الحياة الاخرى من الامور الغيبية وكـان العقل قاصـر ا عن ادر الك اسـر ارها، نـرى هـؤلاء الفلاسفة العقليين يتخبطون في ادر الك هذا الامـور

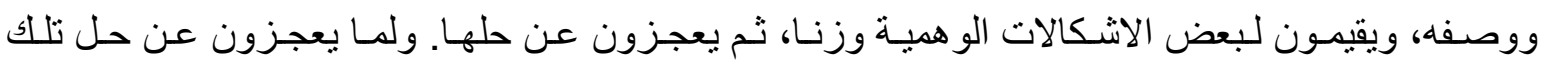
الاشكالات يز عمون ان العقل يحكم باستحالة تلك الامور الغييية في صور ها المنواترة كما صورتها لنا الاديان السماوية وز عما منهم ان ما ورد في الكتب السماوية ليس الا رموزا ومجاز ات عن تلك الاحوال الروحية فيجب تأويلها بحجة ان لا تعارض بين العقل و الدين. و على رأيهم اذ راينا في الظـاهر تعارضـا يجب اخضـاع الدين للعقل، و السؤ ال هنا: لمن يخضع الدين. أ لعقل افلاطون؟ ام لعقل ارسطو؟ ام لعقل ابن سينا؟ ام لعقل ديكارت؟ وعلى ذلك فهل نـؤمن بـامور غيبيـة متعددة وبصورة مختلفة بعضـها عن البعض الاخر بحسب اختلاف فهم هؤلاء الفلاسفة في كل عصر؟ و هل يكون ذلك عقيدة واضحة ثابتة في حياتنا الاجتماعية تهدينا الى الحق و اللى طريق مستقيم وتوصلنا الى سعادة الدنيا والاخرة؟ لا، ليس الامر كما يزعمون. نعم يصح مـا قالوه اذا كان الامـر المختلف فيـه في دائرة العقل و الايـة التي يعارض ظاهر هـا العقل ان كانت من الايـات المتشابهة. اما اذا كان الامر خارجا عن دائرة العقل كالامور الغيبية التي نحن بصددها، وكانت الايـات الدالة على ذلك من الايات المحكمات كالايات الدالة على المعاد الجسماني و النعيم و العذاب الجسمانيين في الاخرة فلا يصح حينذاك تأويلها كما لايصح ان يحكم العقل على ذلك الامر الخارج عن دائرة ادراكه، بل يجب عليه حينئ ان يسلم بتلك الامور الثابتة بالوحي الصحيح وكل مـا للعقل في مثل هذه الامور الغيبية ان يقيم دليلا على امكانها وان يبحث عن حل لتلك الاشكالات يوفق -بالتالي- بين الدين و الفلسفة او بين العقل والايمـان ان استطاع الىى ذلك سبيلا بدل ان يتخبط فيه ويخضع الدين لتعقله. نعم لا يمكن الا الاعتر اف بأن هؤلاء الفلاسفة

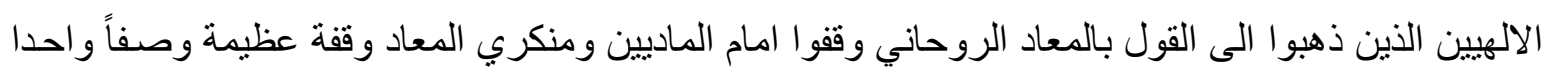
كما لا يمكن الا الاعتر اف بفضلهم في اثبات وجود النفس وروحيتها وخلودها بطرق مختلفة وبر اهين متنو عـة وهئ وبجهود عقلية تستحق كل التقدير ـ. وان ذلك لا يتعارض مع الدين و لايمس اصلا من اصوله لان القول بخلود النفس امر متفق عليه حيث تقره الاديان السماوية كمـا هو و اضح في الايـات الدالة على ذلك. لكنهم تخبطوا فيما بعد ذلك في كيفية الخلود ومراتب النفوس بعد الموت. فالفار ابي مثنلا: بعد ان اكد ان النفس الانسـانية

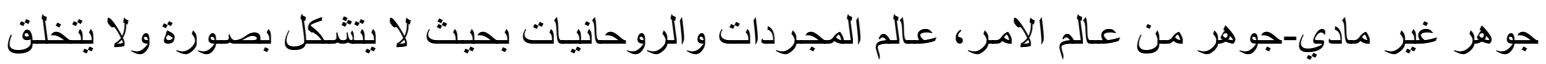
بخلقه ولا يتعرف باشارة ولا يتردد بين سكون وحركة. وباختصار بعد ان قال بتجردها وبساطتها وروحانيتها

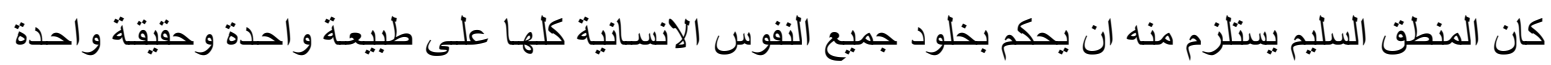
وان اختلفت اوصـافها العارضـة المكتسبة. امـا القول بثلاثنة انواع من النفوس والحكم بخلود نوعين، اعني النفوس الفاضلة و النفوس الفاسدة، دون الحكم بخلود النوع الثالثـ اعني النفوس الجاهلة كمـا صـر ح في كتابـه (ار اء اهل المدينة الفاضلة)- فهذا القول يتعارض مع رايه في طبيعة النفس الانسانية بقطع النظر عن اوصافها العارضة اثناء حياتها البدنية و هو تناقض واضح دون بر هان عقلي او شرعي. 


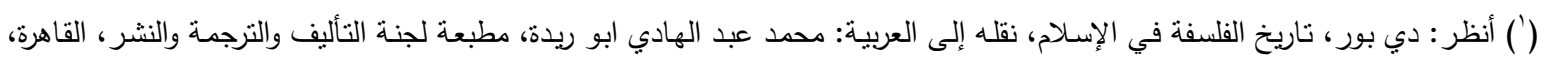

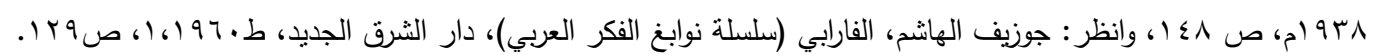

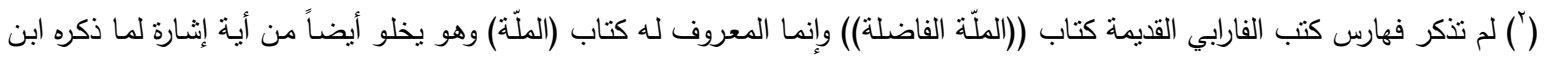

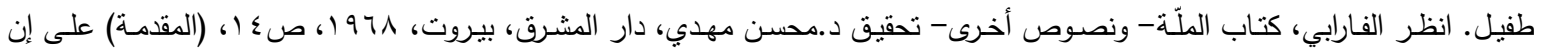

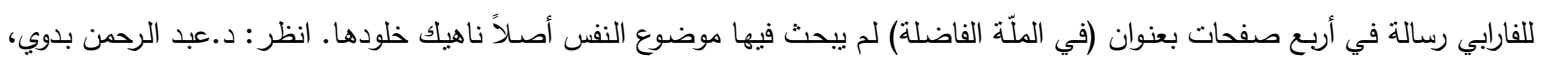

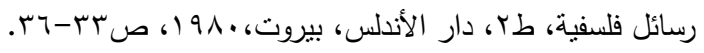

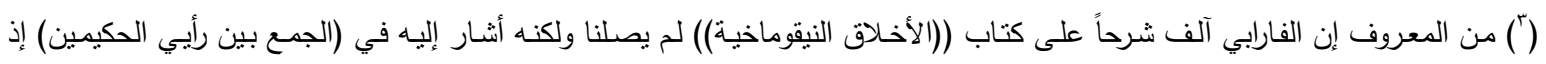
يقول: إن أرسطو في كتابه المعروف بـ ((نيقوماخيا)) إنما ينكلم على القوانين المدنية، على ما بيناه في مواضيع عن شرحنا لذلك الكتاب.

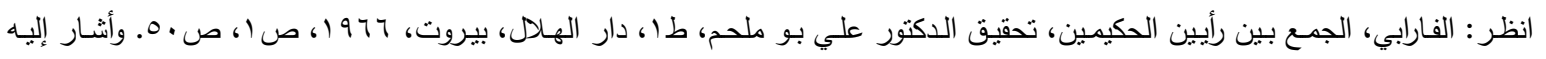

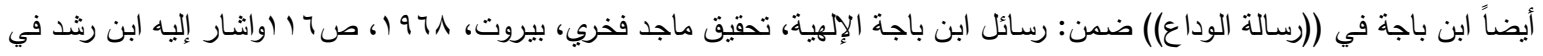

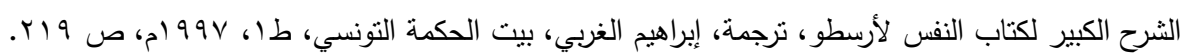

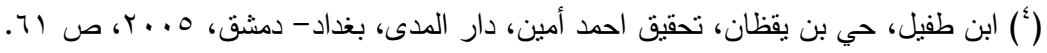

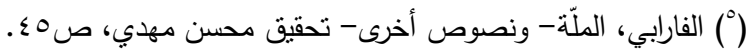

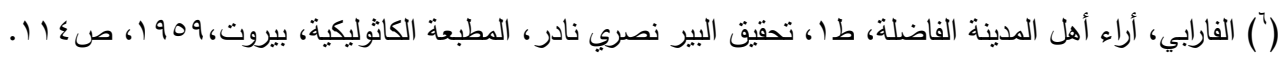

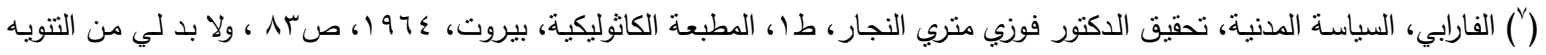

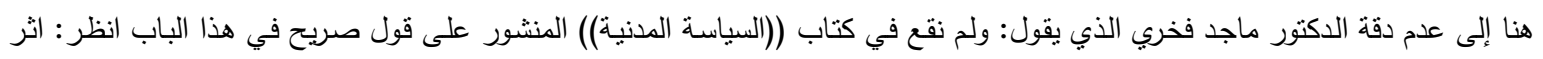

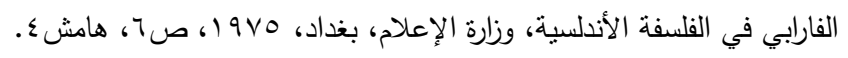

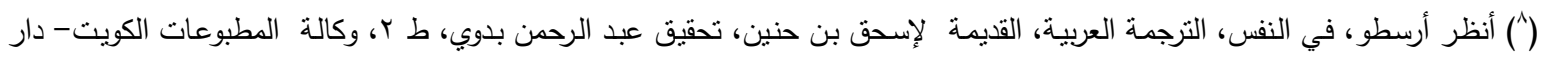

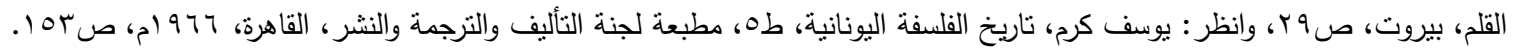

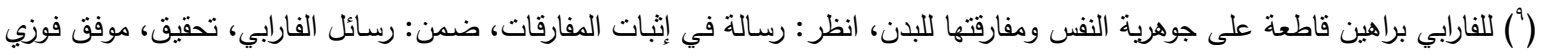

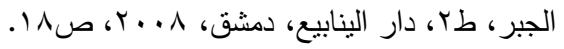

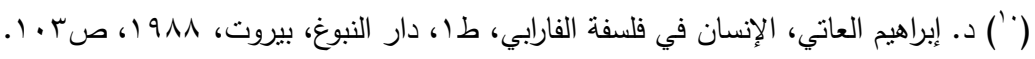

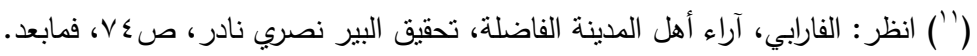

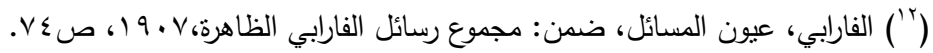

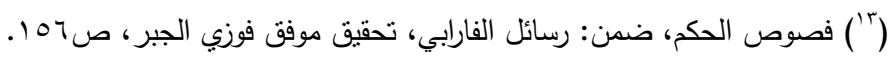

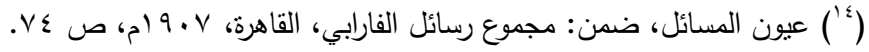

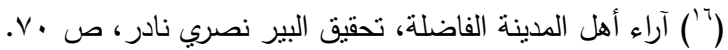

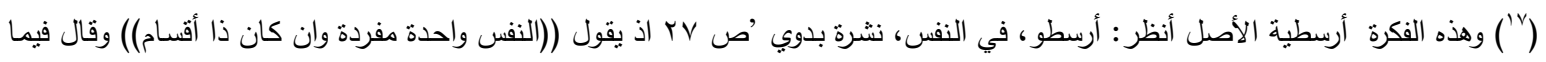

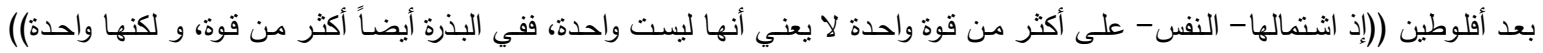

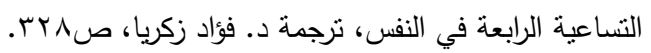

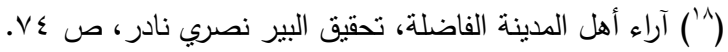

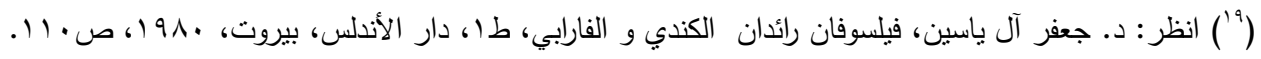

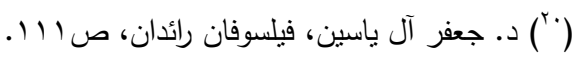

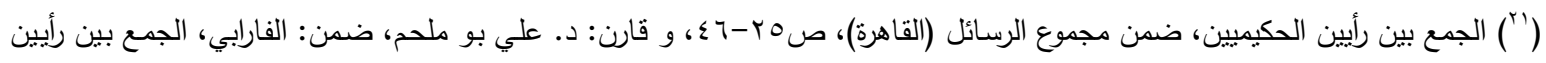

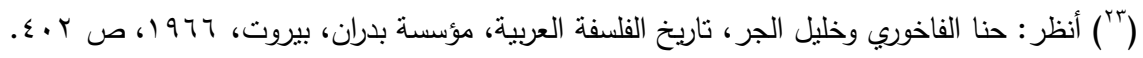

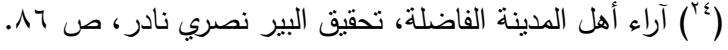

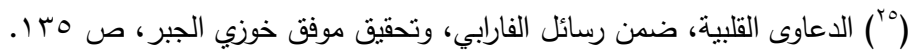

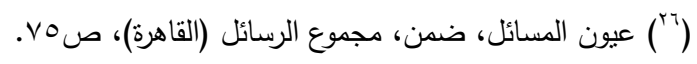




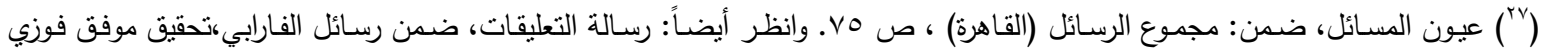
الجبر ، ص10.

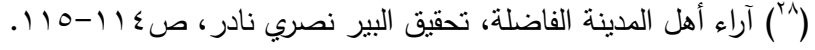

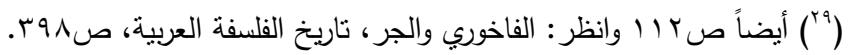

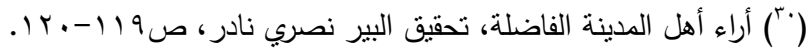

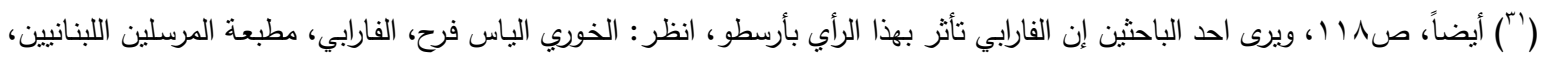
بيروت،

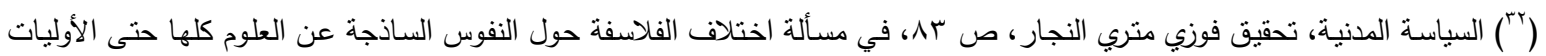

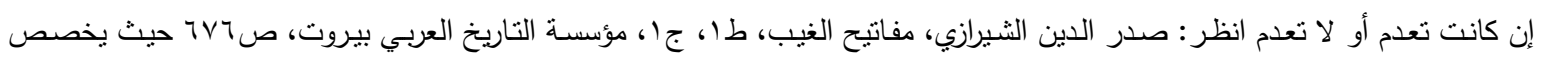

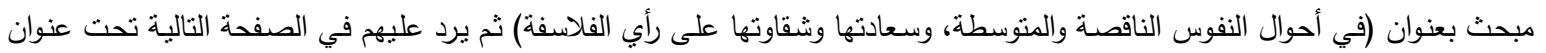
(في أبطال ما ذكروه، وإثارة إلى ما أهملوه) وقد قال ابن سينا (والعقل ليس عجزه عن تصور الأشياء التي هي في غاية المعقولية، والتجريد عن المادة لأمر في ذات تللك الأثياء، والأمر في غزيرة العقل، بل لأجل إن النفس مشغولة في البدن، نحتاج في كثير من الأمور إلى البدن

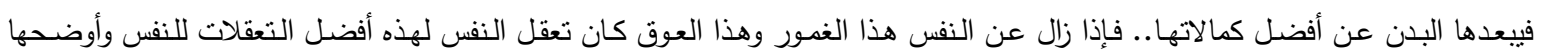

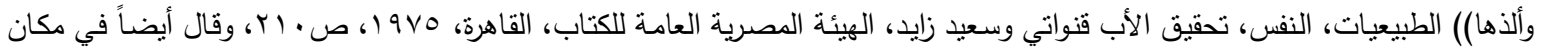
آخر ((فالعقل المستفاد وهو العقل بالفعل من حيث هو كمال.. إن خلص عن البنات البدن وعوارض البدن فحينئذ يجوز أن يتصل بالعقل الفعال تمام

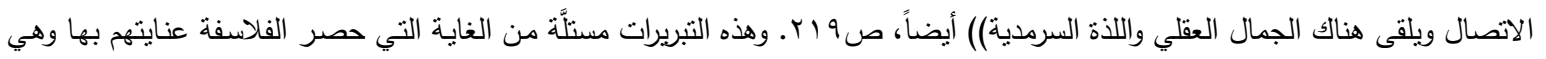

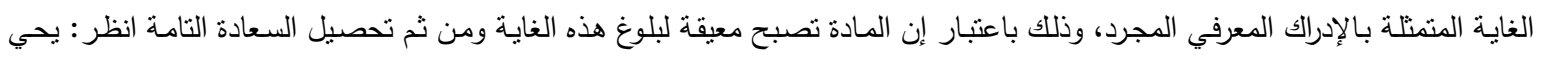

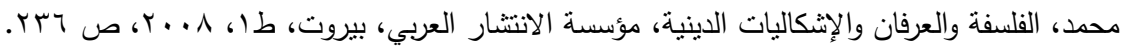

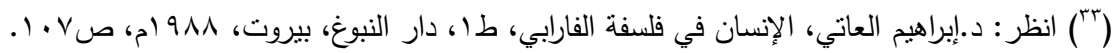

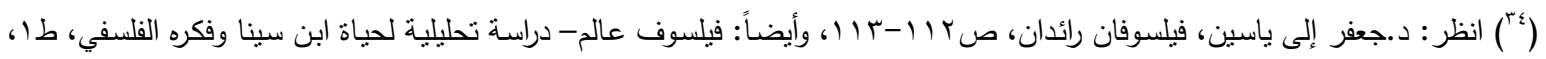

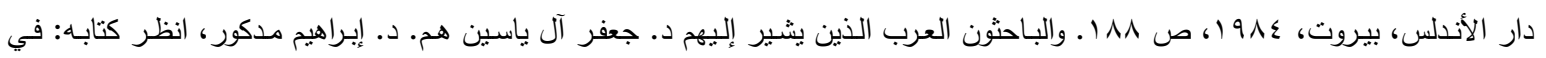

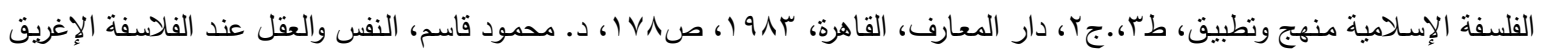

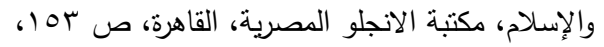

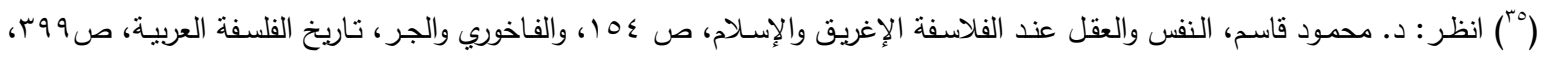

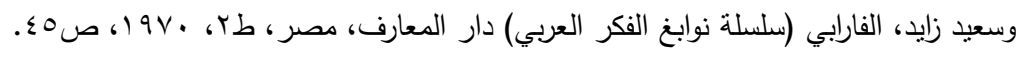

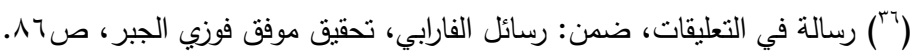

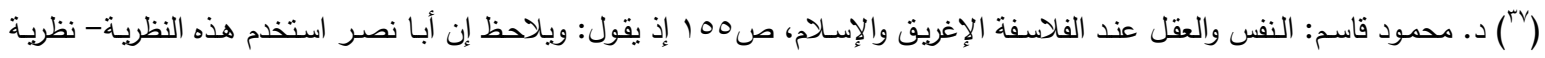
الفيض الأفلاطونية- لتدعيم رأيه السابق. ولذا نراه يسوي بين النفس الكلبة والعقل الفعال.

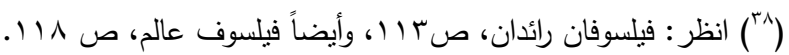

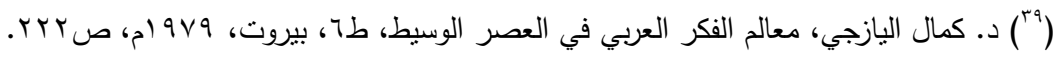

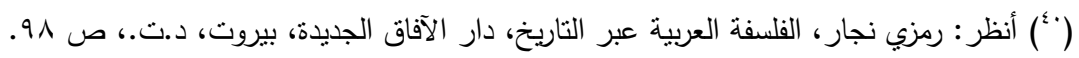

\section{قالتمة الإسادر والمراجع}

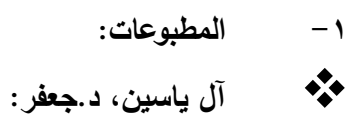

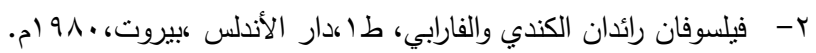

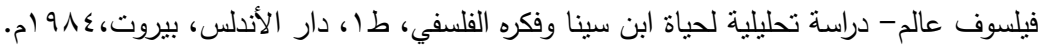

ابن باجة، أبو بكر بن الصائغ:

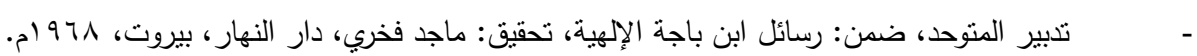

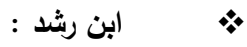

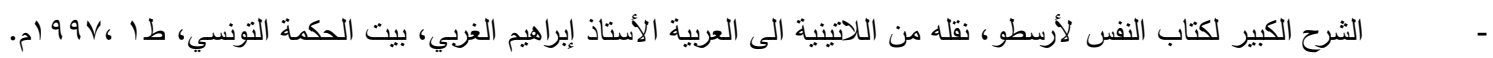

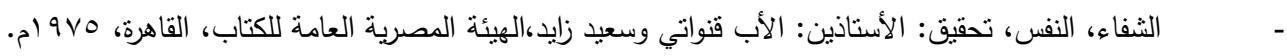




\section{أبن سينا:}

التعليقات، تحقيق: عبد الرحمن بدوي، الهيئة المصرية العامة للكتاب، القاهرة، سلو ام.

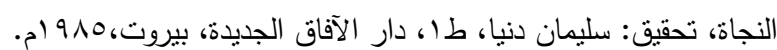

ابن طقيل :

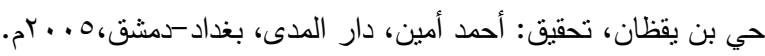

أرسطو طاليس:

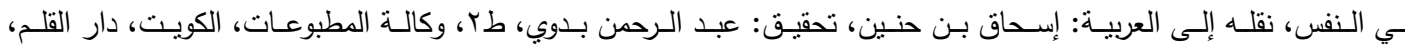

بيروت، . 919 ام.

بدوي،عبد الرحمن:

رسائل فلسفية، طب، دار الأندلس، بيروت، الرمن، 91 ام.

دي بور :

- تاريخ الفلسفة في الإسلام، نقله الى العربية: محمد عبد الهادي أبو ريدة، مطبعة لجنة التأليف والترجمة والنشر ، القاهرة، رب ام. زايد، سعيد:

الفارابي (سلسلة نوابغ الفكر العربي)، طگ، دار المعارف، مصر، • ل9 ام.

الثيرازي، ملا صدرا:

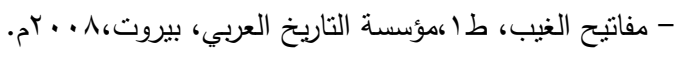

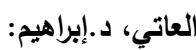

الإنسان في فلسفة الفارابي، ط (،دار النبوغ ،بيروت، $91 \wedge$ ام •

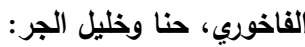

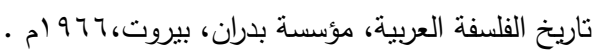

الفارابي، أبو نصر :

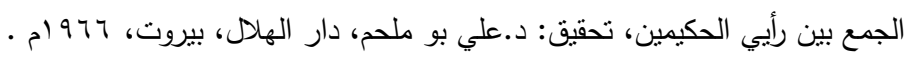

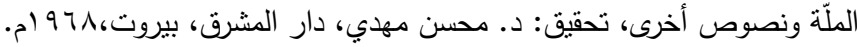

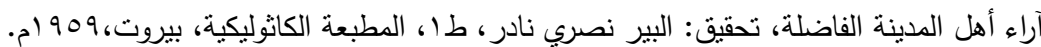

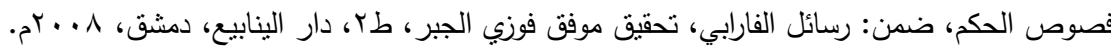

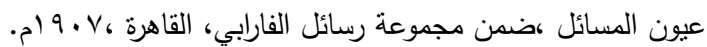

فرح، الخوري إلياس:

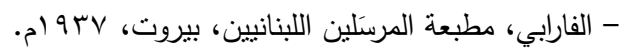

قاسم، محمود:

- النفس والعقل عند الفلاسفة الإغريق والإسلام، مكتبة الأنجلو المصرية، القاهرة، 9 الهود 9 ام.

كرم، يوسف: تارن

تاريخ الفلسفة اليونانية، طه، مطبعة لجنة التأليف والترجمة والنشر ، القاهرة، 977 (م.

محمد، يحيي:

الفلسفة والعرفان والإثكاليات الدينية، طا، مؤسسة الانتشار العربي، بيروت،م ـ . بم.

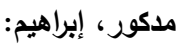

في الفلسفة الإسلامية منهج وتطبيق، طب، دار المعارف، القاهرة، 919 ام .

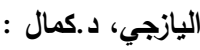

معالم الفكر العربي في العصر الوسيط، طجا، بيروت، 9 أم. 9 م. 